\title{
Review
}

\section{Potential applications of cocoa (Theobroma cacao) on diabetic neuropathy: mini-review}

\author{
Rebeca Kababie-Ameo ${ }^{1}$, Griselda Mericia Rabadán-Chávez ${ }^{2}$, Natalia Vázquez-Manjarrez ${ }^{3}$, \\ Gabriela Gutiérrez-Salmeán ${ }^{1, *}$ \\ ${ }^{1}$ Centro de Investigación en Ciencias de la Salud (CICSA), Facultad de Ciencias de la Salud, Universidad Anáhuac México, 52786 Huixquilucan, \\ Estado de México, Mexico \\ ${ }^{2}$ Departamento de Fisiología, Escuela Nacional de Ciencias Biológicas, Instituto Politécnico Nacional, 07738 Gustavo A. Madero, CDMX, Mexico \\ ${ }^{3}$ Dirección de Investigación, Instituto Nacional de Nutrición y Ciencias Médicas Salvador Zubirán, 14080 Tlalpan, CDMX, Mexico \\ *Correspondence: gabrielasalmean@yahoo.com (Gabriela Gutiérrez-Salmeán) \\ Academic Editor: Chen Chen \\ Submitted: 12 December 2021 Revised: 21 December 2021 Accepted: 21 December 2021 Published: 12 February 2022
}

\begin{abstract}
Diabetes Mellitus is a highly prevalent disease in Mexico and in the world, among whose complications is diabetic neuropathy. DN is a group of disorders that present signs and/or symptoms of peripheral nerve dysfunction and have different clinical manifestations in both peripheral neuropathy and autonomic neuropathy. As a part of the mechanisms by which DN develops, oxidative stress and inflammation have been described. Cocoa is a plant origin product which includes around 300 components and through different studies, it has been suggested that cocoa has different mechanisms of action through which exerts its beneficial effects on health. It has been proposed that cocoa has hypoglycemic, lipid-lowering, antioxidant and anti-inflammatory effects, and thus, potentially have a beneficial direct or indirect effect on diabetic neuropathy. Specially in preclinical studies, the anti-inflammatory and anti-nociceptive effect of cocoa has been evaluated through different mechanisms of action. However, most of the studies presented concerning this complication, are in vitro or preclinical studies, so there is still a great area of opportunity regarding the use of cocoa on diabetic neuropathy.
\end{abstract}

Keywords: Diabetic neuropathy; Cacao; Cocoa; Inflammation; Oxidative stress

\section{Introduction}

\subsection{Diabetes mellitus}

Diabetes Mellitus (DM) is a chronic metabolic disorder characterized by persistent hyperglycemia and occurs due to dysfunction in insulin secretion, resistance, or both [1]. Insulin resistance (IR) is the inability of the hormone to stimulate peripheral glucose uptake, as well as other signaling pathways in different tissues [2,3], and it develops as a consequence of the accumulation of fat in the muscle and organs such as the liver and pancreas. In the latter organ, dysfunction of the pancreatic $\beta$ cells is generated, in addition to inflammation of the islets of Langerhans and cellular apoptosis [4].

Type 2 diabetes (T2D) refers to the relative deficiency of insulin secondary to a progressive dysfunction of its secretion, frequently with a previous period of IR. This type of diabetes accounts for $90-95 \%$ of all cases [5]. According to the International Diabetes Federation, in 2019, it was estimated that the global prevalence of DM in adults aged 20 to 79 years is $9.3 \%$, and for the North American and Caribbean region, it is $13.3 \%$ [1]. In Mexico, according to the National Health and Nutrition Survey (ENSANUT) of 2018 , it was reported that $10.3 \%$ of adults over 20 years of age have a T2D diagnosis, which corresponds to 8.6 million people [6].

\subsection{Diabetic neuropathy}

When a metabolic lack of control related to hyperglycemia persists, macro and microvascular complications can develop. The former involves cardiovascular disease, eg of the large blood vessels, while the latter include retinopathy, nephropathy and diabetic neuropathy (DN) and are caused by pathological changes of the capillaries, which participate in transport of oxygen and nutrients to the different body systems, including the nervous system [1,7]. In studies in Mexico, it has been reported that, on average, $50 \%$ of patients living with DM develop DN, and it is possible to observe it from 5 years after diagnosis of the disease $[8,9]$.

$\mathrm{DN}$ is a group of disorders that present signs and/or symptoms of peripheral nerve dysfunction and have different clinical manifestations in both peripheral neuropathy and autonomic neuropathy $[7,10]$.

As a part of the mechanisms by which DN develops, oxidative stress has been described, which occurs as a consequence of an imbalance between the production of reactive oxygen species (ROS) and endogenous antioxidant systems [11] and the state of inflammation [12]. Hyperglycemia can induce oxidative stress by causing the accumulation of glucose and glycolysis intermediates, and with it, altering the electron transport chain, decreasing the production of $\mathrm{H}_{2} \mathrm{O}$ and ATP and increasing the production of superoxide $\left(\mathrm{O}_{2}^{-}\right)$[11]. 


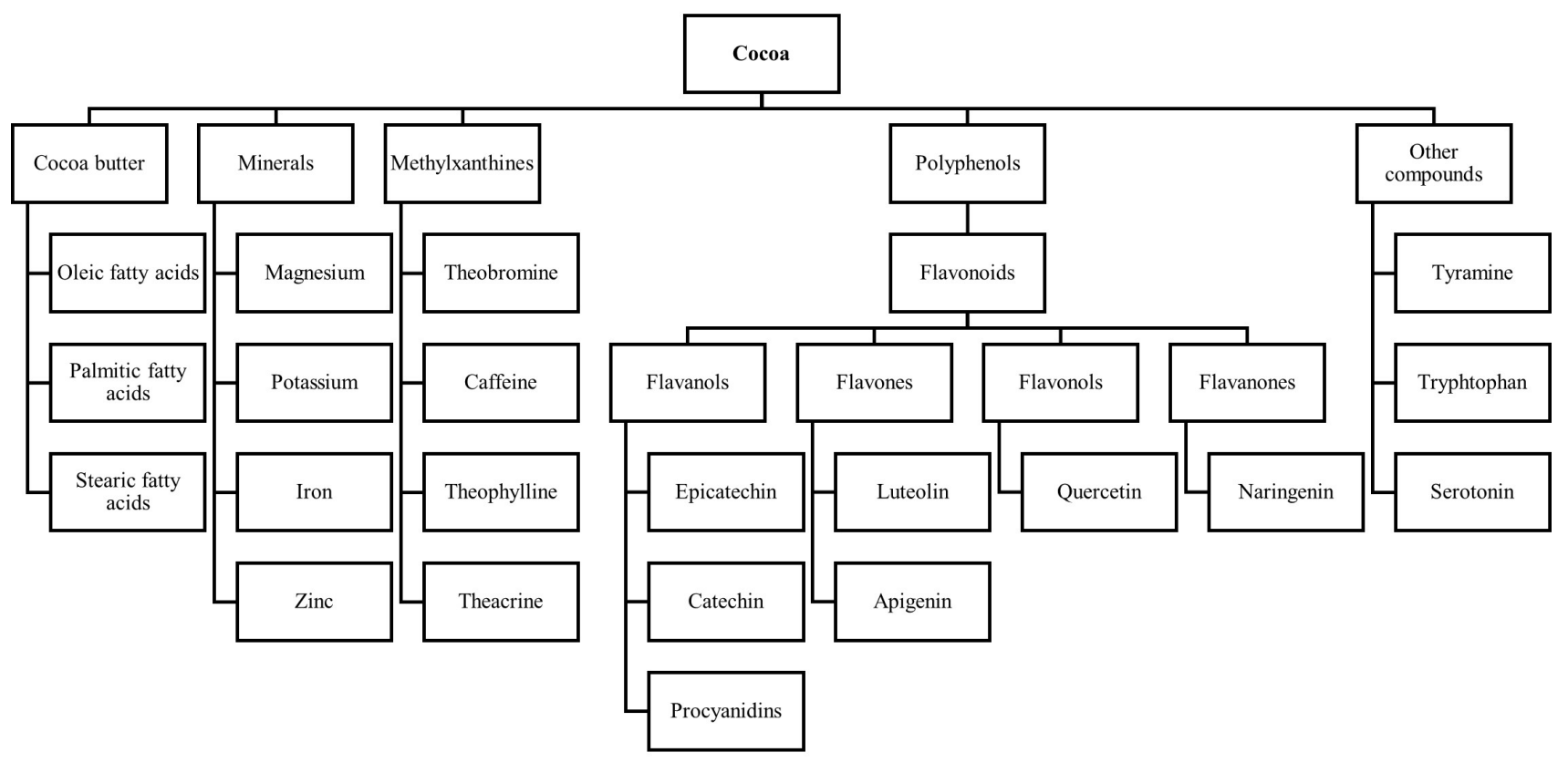

Fig. 1. Cocoa bioactive compounds.

Additionally, hyperglycemia can stimulate macrophages to secrete proinflammatory cytokines such as tumor necrosis factor alpha (TNF- $\alpha$ ), and, in these patients, there is an increase in the expression of $\mathrm{C}$-reactive protein (CRP) and Interleukin-6 (IL-6) [12]. Furthermore, these mechanisms are related since the increase in ROS perpetuates the state of inflammation, just as the proinflammatory cytokines contribute to the increase in ROS [13].

\subsection{Nutritional management}

To date, there is no specific dietary treatment for $\mathrm{DN}$, but the goal is glycemic control, therefore, the American Diabetes Association and the Joslin Diabetes Center, propose weight loss as management for T2D, in case of overweight or obesity and the following macronutrient distribution $[14,15]$.

The carbohydrate recommendation is $40-45 \%$ of the total energy value (TEV), including vegetables, fruits, whole grains and dairy products, as well as 20-35 g of fiber per day; $30-40 \%$ of the TEV of lipids, giving greater relevance to monounsaturated and polyunsaturated fatty acids and limiting saturated fatty acids to less than $10 \%$; protein of 1 to $1.5 \mathrm{~g} / \mathrm{kg}$ adjusted weight/day, which corresponds to $15-30 \%$ of the TEV and less than $2300 \mathrm{mg}$ /day of sodium, that is, 1 teaspoon of salt per day $[14,15]$.

Also, eating patterns such as the Mediterranean diet, Dietary Approaches to Stop Hypertension (DASH) diet, vegetarian diets or low carbohydrate diets could be used to achieve greater metabolic control $[14,15]$.

\section{Theobroma cacao}

Cocoa (Theobroma cacao) is a tree that has been cultivated in several countries of America, including Mexico, and from which one of the most consumed products in the world is derived, chocolate [16].

Cocoa refers to the fruit that has not undergone any transformation, while cocoa powder is the powder that comes from the fruit manufacture, and it is used more frequently in cooking and in daily consumption. On the other hand, chocolate is the product that results after the cleaning, roasting, shelling, grinding and refining cocoa and the addition of milk, sugar or other ingredients [16].

Cocoa has been used, since the Mayas in South America, and it is thought that Christopher Columbus was the first European to meet cocoa beans, which were used as a form of currency [16]. Cocoa not only had an economic use but has also been used for its healing properties, either as a remedy or as a vehicle to deliver other medicines of Mesoamerica [17].

There are reports from European travelers and the Badianus Manuscript, dated between 1536 to 1671, which informed that beverages were prepared with cocoa for therapeutic purposes and the use of cocoa derivatives as nutrients or remedies [18].

Cocoa includes around 300 components, as shown in Fig. 1, among which are cocoa butter, made up of oleic, palmitic and stearic fatty acids; minerals like magnesium, potassium, iron and zinc; methylxanthines such as theobromine and caffeine; compounds like tyramine, tryptophan, and serotonin; and polyphenols, including flavanols such as catechin and epicatechin [19,20]. 
Methylxanthines are alkaloids present in cocoa. Theobromine (3,7-dihydro-3,7-dimethyl-1H-purine, 2,6-dione), is the main alkaloid in cocoa trees, seeds and shells. The second most important methylxanthine is caffeine, followed by theophylline and theacrine [21].

On the other hand, within polyphenols, cocoa is composed of monomers, oligomers and polymers of flavanols. The most common monomers are epicatechin (up to $35 \%$ of the polyphenol content), and \pm catechin. (-) catechin is produced by the epimerization of $(+)$ catechin during the fermentation process [22].

It also contains dimers such as procyanidins B2 (PB2) and $\mathrm{B} 1,(-)$ epicatechin and $(+)$ catechin in greater amounts, and, in lesser amounts, quercetin, quercetin 3-O-glucoside, quercetin 3-O-galactoside, naringenin, luteolin and apigenin [22,23].

\subsection{Flavanol absorption}

The absorption of the different flavanols that the cocoa bean has, varies depending on the type of compound. In vitro studies have shown that procyanidins are hydrolyzed into oligomers in the stomach due to the effect of $\mathrm{pH}$, while monomers such as catechin and epicatechin remain stable $[22,24]$.

Once the monomers and oligomers reach the small intestine, they undergo a phase II biotransformation. This process produces o-methylated, o-sulfated and oglucuronidated metabolites in the intestinal mucosa, which can be absorbed into the bloodstream [22,24].

Monomers such as catechin and epicatechin have higher absorption rates, ranging from 22 to $55 \%$, while dimers and trimers of procyanidins are absorbed, on average, by $0.5 \%$ [22].

Epicatechin appears in plasma in higher concentrations than catechins and Holt et al reported that there is a preference for epicatechin absorption. Similarly, $(+)$ catechin is more bioavailable than (-) catechin [22]. When (-) epicatechin and procyanidin B2 are administered orally, either individually or as components of cocoa powder, the absorption of (-) epicatechin is just as efficient [24].

Procyanidins with a high degree of polymerization cannot be absorbed in the small intestine and reach the colon, where the microbiota microorganisms form phenolic compounds that can be absorbed, reach the liver and undergo a phase II biotransformation [22,24].

In vivo studies have shown that cocoa metabolites can be observed in the circulation 30-60 min after ingestion and reach their maximum peak concentration in plasma within 2-3 h [25]. Epicatechin reaches its maximum concentration in plasma at $2 \mathrm{~h}$, and $20 \%$ of the consumed epicatechin is excreted in urine [26].

A study determined the concentrations of $(-)$ epicatechin and procyanidin B2 after 30 and 120 min of the intake of $0.375 \mathrm{~g}$ of cocoa $/ \mathrm{kg}$ in healthy subjects, with an average contribution of $26.5 \mathrm{~g}$ of cocoa, $323 \mathrm{mg}$ of monomers and
$256 \mathrm{mg}$ of dimers. It was observed that at both 30 and 120 min, the plasma levels of (-) epicatechin were higher than those of procyanidin B2 [24].

Although the absorption of epicatechin is higher, the concentrations of these flavanols are much higher in the intestine than in peripheral tissues. After the ingestion of cocoa, the concentration of epicatechin and procyanidin B2 in circulation are on average, from 0.010 to $6 \mathrm{mcM}$, while after de ingestion of $5 \mathrm{~g}$ of cocoa powder, with an average content of $6 \mathrm{mg}$ of catechin, $25 \mathrm{mg}$ of epicatechin and 235 $\mathrm{mg}$ of procyanidins, the concentrations found in the intestine were $10 \mathrm{mcM}$ of catechin, $43 \mathrm{mcM}$ of epicatechin and $67 \mathrm{mcM}$ of procyanidins. Which may imply a greater requirement to have effects at the peripheral level [22].

\subsection{Methods of extraction}

One of the proposed methods for the extraction of flavanols such as catechin, epicatechin, and alkaloids such as theobromine, caffeine and theophylline, is by supercritical fluid extraction [27].

This super critical state is achieved when a substance is subjected to temperature and pressure beyond its critical point, that is, you have a critical fluid when the distinctive phases of gases and liquids are no longer recognized. The supercritical fluid cannot liquefy even if the pressure is increased, nor can it vaporize even if the temperature is increased [27].

Another method that can be used to obtain polyphenols and antioxidants from cocoa pod husk, such as epicatechin, caffeine and theobromine, is ultrasound, based on the fundamentals of wave frequency. For this, it can be used an ethanol: water solution as extraction solvent with a ratio 1:1 $(\mathrm{v} / \mathrm{v})[28-30]$.

\subsection{Chemical structure and mechanisms of action}

Through different studies, especially in vitro studies, it has been suggested that cocoa has different mechanisms of action through which it exerts its beneficial effects on health [24].

Flavanols like catechins, have a chemical structure consisting of 2 rings ( $\mathrm{A}$ and $\mathrm{B}$ ), joined by 3 carbons that, together with oxygen, form a third heterocyclic ring $(\mathrm{C})$. These flavanols have several hydroxyl groups in their 3 rings, which are associated with antioxidant effects, since they act as electron donors that stabilize free radicals [24].

Also, the degree of polymerization, the number and distribution of hydroxyl groups, influence the type of interaction with cell membranes since flavanols can divide in the hydrophobic part of the membranes or form hydrogen bonds with the polar heads of the membrane of lipids, and when inserted into the lipid bilayer, they can neutralize ROS and radicals that derive from lipid peroxidation [24].

In studies with Jurkat $T$ cells, it has been observed that procyanidins that come from cocoa have interactions with phospholipids that can also be associated with protecting 
the integrity of cell membranes, since they limit the access of some molecules that require binding to the hydrophobic region to generate negative effects [24,31].

Speaking about inflammation, one study suggested that one of the mechanisms by which cocoa might decrease inflammation is through the inhibition of cyclooxygenase 2 (COX-2) or prostaglandin-endoperoxide synthase 2 (PTGS-2) [32].

The structure of COX-2 has 2 heme groups that function as prosthetic groups found un the active site of the enzyme. The $(+)$ catechin and (-) epicatechin bind to COX-2 through the heme group, and thus, inhibit the enzyme, reducing inflammation [32].

Also, by reducing ROS, the release of the active nuclear factor kappa B (NF- $\kappa \mathrm{B})$ complex decreases, reducing inflammation, since this factor induces the transcription of cytokine and chemokine genes, such as TNF- $\alpha$, IL- $1 \beta$ and IL-6 [24,33].

Another direct mechanism that has been proposed is the chelation capacity of metals such as iron and copper, since it has been that, in stated of oxidative stress, there is an alteration in iron homeostasis, which increases its intracellular concentration and promotes ROS production and oxidative protein and DNA damage. This chelation property is a consequence of the presence of a catechol group in ring $\mathrm{B}$ and of the hydroxyl groups, since they have a high affinity for metal ions [24,34].

The consumption of cocoa has been associated with the decrease in blood glucose levels and with the decrease of lipids such as total cholesterol and triglycerides (TG), promoting glucose transporters 4 (GLUT4) translocation in insulin-sensitive tissues through activation of the adenosinmonophosphate activated kinase (AMPK) signaling pathway is part of the mechanism by which hyperglycemia decreases [24]. While the lipid-lowering effect can be reflected by decreasing intestinal absorption of TG, by blocking the interaction between pancreatic lipase and the surface of the emulsified lipid drops. This effect has been attributed both to the peptides in this food and to (-) epicatechin and other oligomers. It may also be due to the decrease in the solubility of intestinal micelles, in turn, decreasing the concentration of cholesterol $[24,35]$.

\section{Health benefits and subjacent metabolic modulations}

The hypoglycemic and lipid-lowering effect are relevant since both alterations are involved in the pathophysiology of DN. The consumption of catechins has been associated with a decrease in hyperglycemia and insulin resistance through the modulation of proinflammatory cytokines such as IL- $1 \beta$, IL- 6 and TNF- $\alpha$, and the activation of signaling pathways that allow maintaining an adequate function of the mitochondrial respiratory chain, and with it, protect cell islets and improve insulin resistance [36].
Also, the different cocoa polyphenols have been related to the attenuation of the postprandial glycemic response and fasting hyperglycemia, improving insulin sensitivity and secretion. Possible mechanisms proposed are inhibition of carbohydrate digestion and glucose absorption at the intestinal level, stimulation of insulin secretion by pancreatic $\beta$ cells, modulation of hepatic glucose release, activation of insulin receptors and their uptake in sensitive tissues, and modulation of intracellular signaling pathways and gene expression [26].

Studies have suggested that cocoa consumption is associated with a decrease in transcription and secretion of adhesion molecules such as intercellular adhesion molecule (ICAM-1) and P-selectin and proinflammatory cytokines such as IL-6 and TNF- $\alpha$ [37].

Monagas et al. [38] evaluated the effects of cocoa consumption on the expression of adhesion molecules and proinflammatory cytokines in subjects at high risk of coronary heart disease, including subjects with diabetes. They found a decrease in ICAM-1 and P-selectin but no difference in other inflammatory markers such as $\mathrm{C}$ reactive protein (CRP) and IL-6 [38].

A study which included individuals with obesity and at risk for insulin resistance and evaluated the effect of cocoa beverages with different flavanol doses, found a decrease in IL-6 and CRP concentrations but no difference on ICAM or fibrinogen values [39].

It has been observed in in vitro studies that epicatechin, catechin and dimeric procyanidins inhibit the activation of NF- $\kappa \mathrm{B}$, and with it, the subsequent inflammatory chain [37].

The effect of catechins from various food sources, such as green tea, on diabetes mellitus has been studied, in which it has been found that catechin can inhibit proinflammatory cytokines and activate AMPK, protein kinase B and other signaling pathways that allow an adequate functioning of the mitochondrial respiratory chain [36].

When there is an adequate functioning of the respiratory chain, there is protection to the pancreatic islets, decrease in insulin resistance and intracellular accumulation of glycogen. Catechin also has inhibitory effects on enzymes that degrade glucose [36].

At the neurological level, it has been observed that the consumption of cocoa and its flavonoids can reduce the risk of neurodegenerative diseases derived from oxidative stress, such as Alzheimer's and Parkinson's disease; reduce depression due to its tryptophan content and its consequent conversion to serotonin; provide protective effects against amyloid $\beta$ protein-induced neurotoxicity and cognitive decline associated with aging and protect nerves from injury and inflammation $[19,26]$.

In preclinical studies, the anti-inflammatory and antinociceptive effect of cocoa has been evaluated through different mechanisms of action, among which are: 
Inhibition of the activation of trigeminal neurons and the expression of proteins involved in nociception in the ganglion and spinal cord [40-42].

Increase in peptides with anti-inflammatory and antinociceptive properties such as protein mitogen activated protein (MAP) kinase phosphatases 1 (MPK-1) [41,42].

Decrease in the expression of the peptide related to the calcitonin gene (CGRP) in the spinal trigeminal nucleus, same as at the glial cell level, it is capable of increasing cell activation, producing a greater amount of proinflammatory molecules [40-42].

Decrease in the expression of inducible nitric oxide synthase (iNOS), which increases the production of nitric oxide and acts as a free radical and participated in the initiation and increase of the inflammatory process and pain $[41,43]$.

Also, proinflammatory cytokines, such as IL- $1 \beta$, IL6 and TNF- $\alpha$, participate in the pathophysiological process of pain, and there are in vitro and in vivo studies that have shown that cocoa can reduce these cytokines, chemokines, ROS, nitric oxide and other molecules that participate in the inflammatory response [41].

In a study carried out with rats with diabetes, Addepalli and Suryavanshi administered 25 and $50 \mathrm{mg} / \mathrm{kg}$ of catechin intraperitoneally, and observed that catechin decreases the neuronal damage caused by oxidative stress and improves antioxidant enzymes. In control rats, an increase in oxidative stress was found in the vagus nerve by observing an increase in malondialdehyde (MDA) levels and a decrease in glutathione, catalase and superoxide dismutase, the same effects were reversed in the treatment groups with catechin [44].

Also, in these intervention groups there was a decrease in the proliferation of Schwan cells, lymphocytic infiltration and demyelination of the vagus nerve, probably secondary to the inhibition of the inflammatory cascade and the increase in myoinositol levels, which modulated demyelination [44].

The following is a summary of the reviewed literature (Table 1, Ref. [32,44-53]). Evidence of the effect of cocoa and its bioactive compounds on T2D, markers of inflammation and oxidative stress and DN is attached.

\section{Discussion}

After reviewing the literature, it is possible to observe a series of limitations and the most important is that the studies described above regarding $\mathrm{DN}$, are mainly in vitro and preclinical studies. This implies that clinical studies are required to specifically evaluate the effect of cocoa on DN, and thus, to be able to determine the necessary doses, supplementation time and the specific bioactive compound or set of compounds that generate the desired effect.

In addition to the type of studies, the doses that were used and the compounds studied are different, which makes it even more difficult to provide recommendations to the population. Even the studies that used the same compounds or products, used different doses.

For example, Munguía et al. [47] in a clinical study, report the use of cocoa extract powder with $80 \mathrm{mg}$ of flavonoids, while in preclinical, Ruzaidi et al. [49] report the use of 1, 2 and $3 \%$ cocoa extract, with a total phenolic content of $285.6 \mathrm{mg} / \mathrm{g}$.

Most of the studies that were reviewed that investigated cocoa extract or its main flavanol, (-) epicatechin, are directly on the pathology of T2D, in which favorable results have been found, finding an improvement in glycemic and lipidic profile, contributing to cardiometabolic control. However, specifically for the management of DN, there is not much evidence yet and the few studies that have been found, use other compounds isolated such as quercetin, proanthocyanidins and naringenin.

Speaking of cocoa, in the studies that were reviewed for the present, cocoa is included in different presentations, either in chocolate, in a beverage, the cocoa extract, or its bioactive components in isolation, so it is difficult to make recommendations or conclusions based on such studies, since its presentation could increase or decrease the bioavailability of bioactive compounds, and furthermore, it is not possible to know if the beneficial effect is due to all of them or to a special compound.

In case a well-defined and strong effect is observed with a specific compound, it would be preferable to consume the isolated bioactive compound, since these (for example, quercetin and naringenin), are found in small amounts in cocoa.

In order to determine if there is strong evidence that allows the recommendation of cocoa or any of its bioactive compounds, it is necessary to define the objective.

Evidence shows that cocoa contributes to an improvement in the cardiometabolic profile, by reducing blood glucose, HbAlc, lipid profile, inflammation markers and oxidative stress markers. The alteration of these parameters contributes to the development of complications of DM, including DN, which could indirectly delay the progression of this microvascular complication.

Published reviews suggest that, due to the characteristics of the main bioactive compounds in cocoa, they could exert beneficial effects on DN. However, no preclinical or clinical studies have yet been conducted to support the use of cocoa or any of its bioactive compounds to prevent, treat, or improve this complication.

\section{Conclusions}

Taking into account the clinical studies reviewed, it is not possible to make recommendations for subjects with $\mathrm{DN}$, but it is feasible to recommend the consumption of chocolate or cocoa powder to individuals with T2D and dyslipidemias since beneficial effects are observed in proinflammatory cytokines, MDA, blood lipids, glycemia and $\mathrm{HbA1c}$, and thus, having a probable indirect effect on 


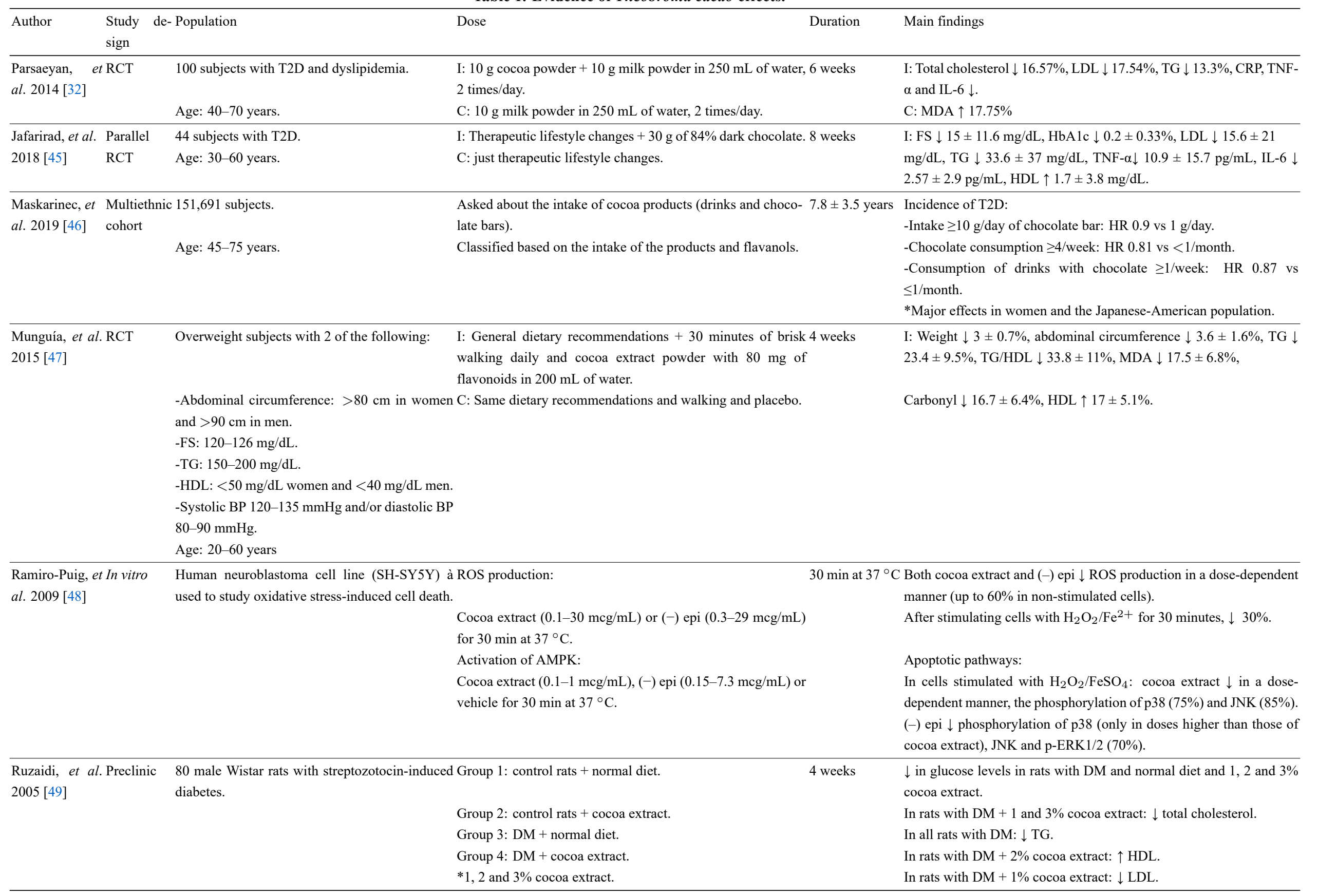




\begin{tabular}{llll}
\hline Author Study de- Population & Table 1. Continued.
\end{tabular}

Duration Main findings

Martín, et al. In vitro INS-1E rat pancreatic cells. 5, 10 and 20 micromoles of epi.

$20 \mathrm{~h}$ prior to the adminis- In cells treated with t-BOOH, epi prevented glutathione depletion and retration of $\mathrm{t}-\mathrm{BOOH}$ for $2 \mathrm{~h}$. covered glutathione peroxidase to pre-stress levels.

Epi $\downarrow$ ROS production.

10-20 mcM of epi recovered the levels of carbonyls similar to the levels of the control group.

$20 \mathrm{mcM}$ of epi $\uparrow$ basal insulin secretion and under glucose stimulation conditions.

\begin{tabular}{|c|c|c|c|c|c|}
\hline $\begin{array}{l}\text { Addepalli, } \\
\text { Suryavanshi. } \\
2018[44]\end{array}$ & Preclinic & $\begin{array}{l}\text { Male Sprague Dawley rats with } \\
\text { streptozotocin-induced diabetes. }\end{array}$ & $\begin{array}{l}\text { C1: normal control. } \\
\mathrm{C} 2 \text { : diabetic rats }+0.5 \% \mathrm{w} / \mathrm{v} \text { CMC. } \\
\text { I1: } 25 \mathrm{mg} / \mathrm{kg} \text { of catechins in } 0.5 \% \mathrm{w} / \mathrm{v} \text { CMC intraperitoneally. } \\
\text { I2: } 50 \mathrm{mg} / \mathrm{kg} \text { of catechins in } 0.5 \% \mathrm{w} / \mathrm{v} \text { CMC intraperitoneally. }\end{array}$ & 28 days & $\begin{array}{l}\text { I1 and 2: glucose } \downarrow \text {, MDA } \downarrow \text {, glutathione and superoxide dismutase } \uparrow \text {. } \\
\text { I2: reversed neuronal damage to normal levels and mitigated neuropathic } \\
\text { lesions in the vagus nerve. }\end{array}$ \\
\hline $\begin{array}{l}\text { Anjaneyulu, } \\
\text { Chopra. } 2003 \\
{[51]}\end{array}$ & Preclinic & $\begin{array}{l}\text { Male albino mice with } \\
\text { streptozotocin-induced diabetes. }\end{array}$ & $\begin{array}{l}\text { Group 1: quercetin vehicle. } \\
\text { Group 2: quercetin in suspension } 50 \mathrm{mg} / \mathrm{kg} \text {. } \\
\text { Group 3: quercetin suspension } 100 \mathrm{mg} / \mathrm{kg} \text {. } \\
\text { Group 4: naloxone }(2 \mathrm{mg} / \mathrm{kg})+\text { quercetin }(100 \mathrm{mg} / \mathrm{kg}) \text {. } \\
\text { Group 5: naloxone }\end{array}$ & 4 weeks & $\begin{array}{l}100 \mathrm{mg} / \mathrm{kg} \text { of quercetin has an antinociceptive effect in control and DM } \\
\text { mice, being more effective in DM mice. } \\
\text { Naloxone + quercetin completely attenuated the antinociceptive effect of } \\
\text { quercetin. }\end{array}$ \\
\hline $\begin{array}{l}\text { Al-Rejaie, et al. } \\
2015 \text { [52] }\end{array}$ & Preclinic & $\begin{array}{l}\text { Male Wistar rats with } \\
\text { streptozotocin-induced diabetes. }\end{array}$ & $\begin{array}{l}\text { C: vehicle treated normal rats. } \\
\text { C2: vehicle treated diabetic rats. } \\
\text { I1: Naringenin } 25 \mathrm{mg} / \mathrm{kg} \text { orally. } \\
\text { I2: } 50 \mathrm{mg} / \mathrm{kg} \text { orally. }\end{array}$ & 5 weeks & $\begin{array}{l}\text { I2: } \downarrow \text { TNF- } \alpha \text {, IL-1 } \beta, \text { IL- } 6 \text { in the sciatic nerve. } \\
\uparrow \text { glutathione and IGF, and superoxide dismutase and catalase activity. }\end{array}$ \\
\hline \multirow[t]{2}{*}{$\begin{array}{l}\text { Ding, et al. } \\
2014 \text { [53] }\end{array}$} & Preclinic & $\begin{array}{l}50 \text { Sprague Dawley rats with } \\
\text { streptozotocin-induced diabetes. }\end{array}$ & $\begin{array}{l}\text { Group 1: normal + vehicle } \\
\text { Group 2: normal + } 250 \mathrm{mg} / \mathrm{kg} \mathrm{GSP} \\
\text { Group 3: T2D + vehicle } \\
\text { Group 4: T2D + GSP } \\
\text { *By gastric tube }\end{array}$ & $\begin{array}{l}24 \text { total weeks ( } 16 \text { weeks } \\
\text { after induction of T2D) }\end{array}$ & $\begin{array}{l}\text { Group 3: } \downarrow \text { the } \mathrm{NCV} \text {, compared to group } 1 \text {, while in group } 4, \uparrow \text { the } \mathrm{NCV} \text {. } \\
\text { In group 3: sciatic nerve damage, dilated mitochondria and endoplasmic } \\
\text { reticulum in Schwann cells. } \\
\text { In group 4: moderate } \uparrow \text { of normal mitochondria and endoplasmic reticulum. }\end{array}$ \\
\hline & In vitro & $\begin{array}{l}\text { Schwann cells cultured from } 10 \\
\text { healthy Sprague Dawley rats and } 2 \\
\text { rats with T2D. }\end{array}$ & $\begin{array}{l}\text { Pretreatment with a combination of catechin and epi at doses } \\
\text { of } 5,10 \text { and } 20 \mathrm{mcM} / \mathrm{L} \text { and induction of stress to endoplasmic } \\
\text { reticulum with } 5 \mathrm{mcg} / \mathrm{mL} \text { of tunicamycin. }\end{array}$ & $48 \mathrm{~h}$ & $\begin{array}{l}\text { The increase of free cytoplasmic } \mathrm{Ca} 2+\text { was blocked. } \\
\text { Pretreatment with } 5 \text { and } 10 \mathrm{mcM} / \mathrm{L} \downarrow \text { stress on the endoplasmic reticulum. }\end{array}$ \\
\hline
\end{tabular}

BP, Blood Pressure; C, Control; CMC, Carboxymethylcellulose; CRP, C-Reactive Protein; DM: Diabetes Mellitus; epi, Epicatechin; FS, Fasting glucose; GSP, Grape Seed Proanthocyanidins; HDL, High-Density

Lipoprotein; HR, Hazard Ratio; I, Intervention; IGF, Insulin Growth Factor; IL-6, Interleukin 6; JNK, c-Jun n-terminal Kinase; LDL, Low-Density Lipoprotein; MDA, Malondialdehyde; NCV, Nerve conduction velocity;

RCT, Randomized Controlled Trial; ROS, Reactive Oxygen Species; T2D, Type 2 Diabetes; t-BOOH, tert-butylhydroperoxide; TG, Triglycerides: TNF- $\alpha$, Tumor Necrosis Factor alpha; $\uparrow$, Increase; $\downarrow$, Decrease. 
neuropathy, using doses that are available on the market and easily consumable. In addition, chocolate is a food accessible to the population and that is generally liked, so it would be easily accepted within the eating habits of different age groups.

These studies evaluated $20 \mathrm{~g}$ of cocoa powder a day with milk and $30 \mathrm{~g}$ of chocolate with $84 \%$ cocoa, quantities that are practical and can be implemented in the diet, however, one of the limitations that may arise when putting it into practice, is that in Mexico there is a great variety of chocolates such as milk chocolate and dark chocolate, each with a different contribution of polyphenols, fats and sugars, with which the same answer would not be seen, and, probably, it's abuse, could be associated with adverse health effects.

\section{Abbreviations}

AMPK, Adenosin-monophosphate activated kinase; BP, Blood pressure; C, Control; CMC, Carboxymethylcellulose; CGRP, Peptide related to the calcitonin gene; COX2, Cyclooxygenase 2; CRP, C-Reactive Protein; DASH, Dietary approaches to stop hypertension; DM, Diabetes Mellitus; DN, Diabetic Neuropathy; ENSANUT, National Health and Nutrition Survey; Epi, Epicatechin; FS, Fasting glucose; GLUT 4, Glucose transporters 4; GSP, Grape Seed Proanthocyanidins; HbA1c, Glycated Hemoglobin A 1 c; HDL, High-Density Lipoprotein; HR, Hazard Ratio; I, Intervention; ICAM-1, Intercellular adhesion molecule 1; IGF, Insulin Growth Factor; IL, Interleukin; iNOS, Inducible nitric oxide synthase; IR, Insulin Resistance; JNK, c-Jun n-terminal Kinase; LDL, Low-Density Lipoprotein; MAP, Mitogen Activated Protein; MDA, Malondialdehyde; NCV, Nerve conduction velocity; NF- $\kappa$ B, Nuclear Factor Kappa B; PTGS-2, Prostaglandin-endoperoxide synthase 2; RCT, Randomized Controlled Trial; ROS, Reactive Oxygen Species; T2D, Type 2 Diabetes; t-BOOH, tert-butylhydroperoxide; TEV, Total Energy Value; TG, Triglycerides; TNF- $\alpha$, Tumor Necrosis Factor alpha.

\section{Author contributions}

RKA collected information and wrote first draft, together with corrections. NVM and GMRC conceived draft and first analyzed such. GGS reviewed, edited, formatted, and chaired the present manuscript.

\section{Ethics approval and consent to participate}

Not applicable.

\section{Acknowledgment}

Not applicable.

\section{Funding}

This research received no external funding.

\section{Conflict of interest}

The authors declare no conflict of interest.

\section{References}

[1] Williams R, Colagiuri S, Almutairi R, Aschner Montoya P, Basit A, Beran D, et al. Atlas de la diabetes de la FID. 2019. Available at: https://iabetesatlas.org/upload/resources/mater ial/20200302_133352_2406-IDF-ATLAS-SPAN-BOOK.pdf (Accessed: 30 November 2021).

[2] Brown AE, Walker M. Genetics of Insulin Resistance and the Metabolic Syndrome. Current Cardiology Reports. 2016; 18: 75 .

[3] Tagi VM, Giannini C, Chiarelli F. Insulin resistance in children. Frontiers in Endocrinology. 2019; 10: 342.

[4] Skyler JS, Bakris GL, Bonifacio E, Darsow T, Eckel RH, Groop $\mathrm{L}$, et al. Differentiation of Diabetes by Pathophysiology, Natural History, and Prognosis. Diabetes. 2017; 66: 241-255.

[5] American Diabetes Association. Classification and diagnosis of diabetes: Standards of Medical Care in Diabetes 2020. Diabetes Care. 2020; 43: S14-S31.

[6] Shamah-Levy T, Vielma-Orozco E, Heredia-Hernández O, Romero-Martínez M, Mojica-Cuevas J, CuevasNasu L, et al. Encuesta Nacional de Salud y Nutrición 2018-19: Resultados Nacionales. 2020. Available at: https:/ensanut.insp.mx/encuestas/ensanut2018/doctos/informe s/ensanut_2018_informe_final.pdf (Accessed: 27 November 2021).

[7] Aguilar Rebolledo F. Neuropatía Diabética. Aspectos prácticos, diagnósticos, terapéuticos y medidas profilácticas. 3ra ed. Editorial Alfil (San Rafael México). 2009; 91-141.

[8] Arellano-Longinos SA, Godínez-Tamay ED, HernándezMiranda MB. Prevalencia de neuropatía diabética en pacientes con diabetes mellitus tipo 2 en una clínica regional del Estado de México. Atención Familiar. 2018; 25: 7-11.

[9] Ibarra CT, Rocha JJ, Hernández R, Nieves RE, Leyva R. Prevalencia de neuropatía periférica en diabéticos tipo 2 en el primer nivel de atención. Revista Médica de Chile. 2012; 140: 11261131.

[10] American Diabetes Association. Microvascular complications and foot care: Standards of Medical Care in Diabetes 2020. Diabetes Care. 2020; 43: S135-51.

[11] Pang L, Lian X, Liu H, Zhang Y, Li Q, Cai Y, et al. Understanding Diabetic Neuropathy: Focus on Oxidative Stress. Oxidative Medicine and Cellular Longevity. 2020; 2020: 1-13.

[12] Ristikj-Stomnaroska D, Risteska-Nejashmikj V, Papazova M. Role of Inflammation in the Pathogenesis of Diabetic Peripheral Neuropathy. Open Access Macedonian Journal of Medical Sciences. 2019; 7: 2267-2270.

[13] Hussain T, Tan B, Yin Y, Blachier F, Tossou MCB, Rahu N. Oxidative Stress and Inflammation: what Polyphenols can do for us? Oxidative Medicine and Cellular Longevity. 2016; 2016: $1-9$.

[14] American Diabetes Association. Facilitating behavior change and well-being to improve health outcomes: Standards of Medical Care in Diabetes 2021. Diabetes Care. 2021; 44: S53-S72.

[15] Hamdy O, Ganda OP, Maryniuk M, Gabbay RA, Joslin Clinical Oversight Committee. Clinical Nutrition Guideline for Overweight and Obese Adults With Type 2 Diabetes (T2D) or Prediabetes, or Those at High Risk for Developing T2D. 2018. Available at: https://joslin-prod.s3.amazonaws.com/www.josl in.org/assets/2020-07/2ebdm_joslin_chapter_2.pdf (Accessed: 25 September 2021).

[16] Montagna M, Diella G, Triggiano F, Caponio GR, de Giglio O, Caggiano G, et al. Chocolate, "Food of the Gods": History, Science, and Human Health. International Journal of Environmental 
Research and Public Health. 2019; 16:4960.

[17] Katz DL, Doughty K, Ali A. Cocoa and Chocolate in Human Health and Disease. Antioxidants \& Redox Signaling. 2011; 15: 2779-2811.

[18] Lippi D. Chocolate in History: Food, Medicine, Medi-Food. Nutrients. 2013; 5: 1573-84.

[19] De Araujo QR, Gattward JN, Almoosawi S, Parada Costa Silva MDGC, de Santana Dantas PA, de Araujo Júnior QR. Cacao and Human Health: from Head to Foot-A Review. Critical Reviews in Food Science and Nutrition. 2013:1-12.

[20] Goya L, Martín M, Sarriá B, Ramos S, Mateos R, et al. Effect of Cocoa and Its Flavonoids on Biomarkers of Inflammation: Studies of Cell Culture, Animals and Humans. Nutrients. 2016; 8: 212.

[21] Vázquez-Ovando A, Ovando-Medina I, Adriano-Anaya L, Betancur-Ancona D, Salvador-Figueroa M. Alcaloides y polifenoles del cacao, mecanismos que regulan su biosíntesis y sus implicaciones en el sabor y aroma. Archivos Latinoamericanos de Nutrición. 2016; 66: 239-254.

[22] Strat KM, Rowley TJ, Smithson AT, Tessem JS, Hulver MW, Liu D, et al. Mechanisms by which cocoa flavanols improve metabolic syndrome and related disorders. The Journal of Nutritional Biochemistry. 2016; 35: 1-21.

[23] Martin MA, Goya L, Ramos S. Protective effect of tea, red wine and cocoa in diabetes. Evidences from human studies. Food and Chemical Toxicology. 2017; 109: 302-314.

[24] Jaramillo Flores ME. Cocoa flavanols: natural agents with attenuating effects on metabolic syndrome risk factors. Nutrients. 2019; 11: 751.

[25] Bernatova I. Biological activities of (-)-epicatechin and (-)epicatechin-containing foods: Focus on cardiovascular and neuropsychological health. Biotechnology Advances. 2018; 36: 666-681.

[26] Andújar I, Recio MC, Giner RM, Ríos JL. Cocoa Polyphenols and their Potential Benefits for Human Health. Oxidative Medicine and Cellular Longevity. 2012; 2012: 1-23.

[27] Azmir J, Zaidul ISM, Rahman MM, Sharif KM, Mohamed A, Sahena $\mathrm{F}$, et al. Techniques for extraction of bioactive compounds from plant materials: a review. Journal of Food Engineering. 2013; 117: 426-436.

[28] Sotelo L, Alvis A, Arrázola G. Evaluación de epicatequina, teobromina y cafeína en cáscaras de cacao (Theobroma cacao L.), determinación de su capacidad antioxidante. Revista Colombiana de Ciencias Hortícolas. 2015; 9: 124-134.

[29] Pico-Hernández SM, Murillo-Méndez CJ, López-Giraldo LJ. Extraction, separation, and evaluation of antioxidant effect of the different fractions of polyphenols from cocoa beans. Revista Colombiana de Química. 2020; 49: 19-27.

[30] Yusof AHM, Abd Gani SS, Zaidan UH, Halmi MIE, Zainudin BH. Optimization of an ultrasound-assisted extraction condition for flavonoid compounds from cocoa shells (Theobroma cacao) using response surface methodology. Molecules. 2019; 24: 711 .

[31] Verstraeten S, Oteiza P, Fraga C. Membrane effects of Cocoa Procyanidins in Liposomes and Jurkat T Cells. Biological Research. 2004; 37: 293-300.

[32] Parsaeyan N, Mozaffari-Khosravi H, Absalan A, Mozayan MR. Beneficial effects of cocoa on lipid peroxidation and inflammatory markers in type 2 diabetic patients and investigation of probable interactions of cocoa active ingredients with prostaglandin synthase-2 (PTGS-2/COX-2) using virtual analysis. Journal of Diabetes \& Metabolic Disorders. 2014; 13: 30.

[33] Echeverri R N, Mockus S I. Factor Nuclear kB (NF-kB): Signalosoma y su importancia en enfermedades inflamatorias y cáncer. Revista de la Facultad de Medicina. 2008; 56: 133-146.

[34] Cherrak S, Mokhtari-Soulimane N, Berroukeche F. In Vitro Antioxidant versus Metal Ion Chelating Properties of
Flavonoids: A Structure-Activity Investigation. PLoS ONE. 2016; 11:e0165575.

[35] Coronado-Cáceres L, Rabadán-Chávez G, Mojica L, Hernández-Ledesma $\mathrm{B}$, Quevedo-Corona L, Lugo Cervantes E. Cocoa (Theobroma cacao L.) Seed Proteins' Anti-Obesity Potential through Lipase Inhibition Using In Silico, In Vitro and In Vivo Models. Foods. 2020; 9: 1359.

[36] Bai L, Li X, He L, Zheng Y, Lu H, Li J, et al. Antidiabetic Potential of Flavonoids from Traditional Chinese Medicine: A Review. the American Journal of Chinese Medicine. 2019; 47: 933-957.

[37] Ellinger S, Stehle P. Impact of cocoa consumption on inflammation processes-A critical review of randomized controlled trials. Nutrients. 2016; 8: 321.

[38] Monagas M, Khan N, Andres-Lacueva C, Casas R, Urpí-Sardà $\mathrm{M}$, Llorach R, et al. Effect of cocoa powder on the modulation of inflammatory biomarkers in patients at high risk of cardiovascular disease. the American Journal of Clinical Nutrition. 2009; 90: 1144-1150.

[39] Stote KS, Clevidence BA, Novotny JA, Henderson T, Radecki SV, Baer DJ. Effect of cocoa and green tea on biomarkers of glucose regulation, oxidative stress, inflammation and hemostasis in obese adults at risk for insulin resistance. European Journal of Clinical Nutrition. 2012; 66: 1153-1159.

[40] Abbey MJ, Patil VV, Vause CV, Durham PL. Repression of calcitonin gene-related peptide expression in trigeminal neurons by a Theobroma cacao extract. Journal of Ethnopharmacology. 2008; 115: 238-248.

[41] De Feo M, Paladini A, Ferri C, Carducci A, Del Pinto R, Varrassi G, et al. Anti-Inflammatory and Anti-Nociceptive Effects of Cocoa: a Review on Future Perspectives in Treatment of Pain. Pain and Therapy. 2020; 9: 231-240.

[42] Cady RJ, Denson JE, Durham PL. Inclusion of cocoa as dietary supplement represses expression of inflammatory proteins in spinal trigeminal nucleus in response to chronic trigeminal nerve stimulation. Molecular Nutrition \& Food Research. 2013; 57: 996-1006.

[43] Cady RJ, Durham PL. Cocoa-enriched diets enhance expression of phosphatases and decrease expression of inflammatory molecules in trigeminal ganglion neurons. Brain Research. 2010; 1323: 18-32.

[44] Addepalli V, Suryavanshi SV. Catechin attenuates diabetic autonomic neuropathy in streptozotocin induced diabetic rats. Biomedicine \& Pharmacotherapy. 2018; 108: 1517-1523.

[45] Jafarirad S, Ayoobi N, Karandish M, Jalali M, Haghighizadeh M, Jahanshahi A. Dark chocolate effect on serum adiponectin, biochemical and inflammatory parameters in diabetic patients: a randomized clinical trial. International Journal of Preventive Medicine. 2018; 9: 86

[46] Maskarinec G, Jacobs S, Shvetsov Y, Boushey CJ, Setiawan VW, Kolonel LN, et al. Intake of cocoa products and risk of type-2 diabetes: the multiethnic cohort. European Journal of Clinical Nutrition. 2019; 73: 671-678.

[47] Munguía L, Gutiérrez-Salmeán G, Hernández M, Ortiz A, Sánchez ME, Nálera N, et al. Beneficial effects of a flavonolenriched cacao beverage on anthropometric and cardiometabolic risk profile in overweight subjects. Revista Mexicana de Cardiología. 2015; 26: 78-86.

[48] Ramiro-Puig E, Casadesús G, Lee H, Zhu X, McShea A, Perry $\mathrm{G}$, et al. Neuroprotective effect of cocoa flavonids on in vitro oxidative stress. European Journal of Nutrition. 2009; 48: 5461.

[49] Ruzaidi A, Amin I, Nawalyah AG, Hamid M, Faizul HA. The effect of Malaysian cocoa extract on glucose levels and lipid profiles in diabetic rats. Journal of Ethnopharmacology. 2005; 98: $55-60$. 
[50] Martín MÁ, Fernández-Millán E, Ramos S, Bravo L, Goya L. Cocoa flavonoid epicatechin protects pancreatic beta cell viability and function against oxidative stress. Molecular Nutrition \& Food Research. 2014; 58: 447-456.

[51] Anjaneyulu M, Chopra K. Quercetin, a bioflavonoid, attenuates thermal hyperalgesia in a mouse model of diabetic neuropathic pain. Progress in Neuro-Psychopharmacology and Biological Psychiatry. 2003; 27: 1001-1005.
[52] Al-Rejaie SS, Aleisa AM, Abuohashish HM, Parmar MY, Ola MS, Al-Hosaini AA, et al. Naringenin neutralises oxidative stress and nerve growth factor discrepancy in experimental diabetic neuropathy. Neurological Research. 2015; 37: 924-933.

[53] Ding Y, Dai X, Zhang Z. Proanthocyanidins protect against early diabetic peripheral neuropathy by modulating endoplasmic reticulum stress. The Journal of Nutritional Biochemistry. 2014; 25: 765-772. 